\title{
UMA HIPÓTESE SOBRE A DIMENSÃO ANTROPOLÓGICA DO LIVRO EM “EL LIBRO", DE JORGE LUIS BORGES
}

Henrique de Oliveira Lee*

RESUMO: Jorge Luis Borges realizou em Belgrano uma palestra sobre um pequeno esboço de uma história do livro. Em sua palestra Borges isolou três conceitos ou paradigmas de livro: o livro dos antigos, o livro sagrado e o livro-nação. A partir da fundamentação teórica da Antropologia Literária de Wolfgang Iser formulamos uma hipótese sobre a dimensão antropológica do livro. Primeiramente, aproximamos a noção de livro em Borges com a noção de artefato da Antropologia, para então aborda os paradigmas de livro de Borges como uma descricão de certos conjuntos de relações recursivas entre o artefato livro e seus leitores.

PALAVRAS-CHAVE: livro; Jorge Luis Borges; Antropologia Literária.
* holiveiralee@gmail.com

Doutor em Literatura Comparada. Professor da Universidade Federal do Mato Grosso.

ABSTRACT: Jorge Luis Borges delivered a conference at Belgrano about a sketch of a history of the book. During his speech Borges isolated three concepts or paradigms of the book: the book of the ancients, the holly book and the book-nation. Departing from the theoretical ground of Iser's Literary Anthropology we have formulated na hipotheses about the anthropological dimension of the book. First we pointed out some of the convergence between the book in Borges and Anthropology's notion of artifact then we approached Borge's book paradigms as descriptions of a set of recursive relations between the artifact book and its readers.

KEYWORDS: book; Jorge Luis Borges; Literary Anthropology 
1. LEROI-GOURHAN. Gesture and speech, p. 247.

\section{O LIVRO COMO ARTEFATO}

O paleontólogo e antropólogo francês André LeroiGourhan sustenta, em uma obra publicada em 1964, a hipótese de que os artefatos e ferramentas são como uma secreção do corpo e do cérebro do antropoide. Tal descrição dos artefatos e ferramentas como "secreções" sugere a existência de uma relação recursiva entre o homem e seus artefatos que parece demandar a complexificação de qualquer esquema de oposição simples entre natureza e cultura.

We have seen that human evolution from Homo sapiens onward has been a story of more and more radical separation between the rate of change affecting the body still governed by the geological time scale and that of change affecting tools, which now occurs with every generation. If the species was to survive, some accommodation was necessary, and this accommodation was bound not only to affect our technical habits but also to involve thoroughgoing changes in the laws according to which individuals group themselves together. Of course the parallel with the zoological world cannot be maintained except by way of paradox, but we cannot completely dismiss the thought that some species change takes place whenever humankind replaces both its tools and its institutions.

A relação de recursividade entre o antropoide e seus artefatos poderia ser descrita da seguinte maneira: o homem produz artefatos, mas, ao fazê-lo, cria, inadvertidamente, as condições das mudanças de comportamento de sua espécie. É nesse sentido que Leroi-Gourhan afirma que as mudanças na espécie humana acarretadas pelo do uso de artefatos tem todas as características de uma evolução biológica. ${ }^{2}$

Curiosamente, em uma palestra na Universidade de Belgrano, em maio de 1978, Jorge Luis Borges, sem nenhuma referência direta a ele, parece aplicar as consequências da hipótese de Leroi-Gourhan sobre "o mais assombroso dos artefatos”. ${ }^{2}$ Borges argumenta, em consonância com o paleontólogo, que os diversos artefatos e as ferramentas mais primitivas como arados e lanças são extensões do corpo, e mesmo instrumentos como o microscópio e o telescópio, que demandariam aprimoramento tecnológico, não seriam mais do que extensões do olho, assim como o telefone seria uma extensão da voz.

Pero el libro es otra cosa, el libro es una extensión de la memoria y de la imaginación. [...] En Cesar y Cleopatra de Shaw, cuando se habla de la biblioteca de Alejandria se dice que es la memoria de la humanidad. Eso es el libro y es algo más también, la imaginación. Porque, ¿qué es nuestro passado sino una serie de sueños? ¿Qué diferencia puede haber entre recordar sueños y recordar el pasado? Ésa es la función que realiza el libro. ${ }^{3}$
2. LEROI-GOURHAN. Gesture and speech, p. 242. 
Não há nada de surpreendente na afirmação de que o artefato livro realiza a função de expandir essas duas faculdades, entretanto, estabelecer uma relação de indissociabilidade ao ponto de torná-las quase indistintas é que parece contrariar todo nosso saber tácito sobre o que sejam a memória e a imaginação. É crucial notar que Borges não diz que o livro expande ora a memória, ora a imaginação, mas que o próprio ato de recordar é um ato imaginativo. A articulação entre memória e imaginação pode, a princípio, parecer algo meramente casual no texto de Borges, mas o exame das suas implicações possibilita entrever a dimensão antropológica do livro na relação recursiva entre este e seus leitores.

Durante a palestra de Belgrano, Borges revela que havia pensado, em mais de uma ocasião, em escrever uma "História do Livro". Pode-se pensar a palestra de Belgrano como um rascunho desse projeto não executado de Borges. Borges julga que grande parte desse trabalho já fora antecipado por Oswald Spengler - em algumas "preciosas páginas sobre o livro" que compõem a obra The decline of the west - e declara que sua palestra irá se ater basicamente ao que já foi dito pelo historiador alemão, com o acréscimo de algumas observações sobre a literatura. Apesar de afirmar a adesão ao esquema esboçado nessas poucas páginas do livro de Spengler, Borges, ao isolar os conceitos de livro antigo - a que chamaremos aqui de livro-simulacro -, livro sagrado e livro-nação, parece dispor deles apenas como paradigmas da relação entre livro e leitor - que poderiam inclusive coexistir simultaneamente num mesmo momento - sem qualquer subserviência à pesada teleologia histórica presente no pensamento do historiador alemão. Os três paradigmas elencados por Borges formam uma tipologia de crenças, sentidos e valores atribuídos aos livros, e cada um deles é referenciado a um determinado momento histórico. No entanto, a referenciação histórica de tais conceitos ou paradigmas de livro são apenas coordenadas amplas de caráter difuso, sem nenhuma pretensão de exatidão ou exaustão descritiva.

Mesmo com essas imprecisões históricas, o que "El libro" tem, ao nosso ver, de fecundo é o fato de que os conceitos de livro articulam uma correspondência entre determinados modos de usar o artefato livro com determinados modelos civilizatórios, caracterizados por Borges como momentos históricos, fornecendo, assim, visibilidade a uma hipótese antropológica sobre o livro. Tal hipótese descreve um conjunto de relações recursivas, de produção mútua, entre uma determinada comunidade de leitores situada historicamente e o seu respectivo artefato livro. Se, como aposta Borges, o livro é um artefato que realiza uma extensão da memória e da imaginação, cada paradigma de livro pode ser pensado como uma descrição de certos modos de utilização dessas duas faculdades humanas, e suas consequências. Talvez, o mais interessante seja justamente notar o que cada um desses 
4. BRANDÃO. Grafias da identidade, p. 10 paradigmas de livro, apesar de serem historicamente datados, podem revelar quando contrastados com o estatuto contemporâneo dado ao artefato livro, cuja intensa mudança, seja nos seus usos ou no seu suporte físico ou virtual, podemos testemunhar atualmente.

\section{UMA HIPÓTESE ANTROPOLÓGICA SOBRE O LIVRO}

O teórico alemão Wolfgang Iser cunhou o termo Antropologia Literária para nomear uma perspectiva de abordagem da literatura que investiga a demanda do humano por ficções literárias. Tal perspectiva pode ser contextualizada como uma tentativa de resposta a uma polarização frequentemente retomada no âmbito dos diversos debates entre as diversas correntes de abordagens críticas do texto literário. Segundo Luis Alberto Brandão, essa polarização pode ser descrita como um embate

que contrapõe a perspectiva formalista ou imanentista - cuja premissa básica é haver uma especificidade no modo como a linguagem literária se configura, [...] à perspectiva sociológica ou culturalista, a qual se esforça para entender a literatura em seu vínculo, mais ou menos deterministas, com fatores históricos e sociais. ${ }^{4}$

Escapar a essa polarização só foi possível pelo esforço de redefinir os termos e pressupostos pelos quais se pensava o objeto literário. E desse modo, produzir "um modelo heurís-

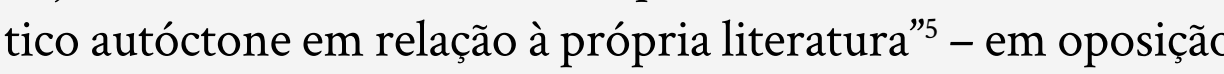
ao hábito de aplicar modelos heurísticos de outras disciplinas aos estudos literários, como na perspectiva sociológica ou culturalista - sem que isso implique, entretanto, uma concepção do fenômeno literário como entidade autossuficiente, sem ligação com fenômenos advindos do mundo extraliterário, como nas perspectivas formalistas e imanentistas.

Fez-se necessário, portanto, questionar a noção de ficção tal como vinha sendo definida pelo saber tácito:

Os textos "fíccionados" serão de fato tão ficcionais e os que assim não se dizem serão de fato isentos de ficções? Como não se pode negar a legitimidade da pergunta, cabe indagar se o "saber tácito" a opor ficção e realidade ainda pode ser de alguma valia para a descrição dos textos ficcionais. [...] A determinação nitidamente ontológica atuante nesse tipo de "saber tácito" caracteriza a ficção justamente pela eliminação dos predicados que serão atribuídos à realidades.

Ao abandonar qualquer possibilidade de fornecer uma definição ontológica da ficção, Iser propõe pensar sua possibilidade de definição a partir de uma lógica relacional. Desse modo, a Antropologia Literária não parte de uma concepção estática do que é o "humano" e do que é a "ficção", assume,
5. ISER. O fictício e o imaginário p. 10-11.
6. ISER. Atos de fingir ou o que é fictício no texto ficcional, p. 385 
entretanto, como um atributo fundamental do humano a sua plasticidade, para entender a ficção como a operação que converte esse atributo em texto.

Nesse sentido, a definição de ficção é relacional porque será sempre uma variável dependente de como o humano irá defini-la, ainda que provisoriamente, através dos diversos usos que faz dela, e, inversamente, é por meio das ficções que o humano, cujo principal atributo é a plasticidade, ganha definições provisórias. Essa relação entre as ficções e o humano pode ser descrita exatamente nos moldes da relação recursiva entre o homem e o artefato tal como formulada por Leroi-Gourhan

Para Iser, convencionamos chamar de ficções literárias os discursos que autodesnudam a sua condição ficcional. Entretanto, outros tipos de discursos, que não revelam a sua condição ficcional, são igualmente ficcionais, só que utilizados com finalidades explicativas. Iser destacou dois modos básicos de se classificar as ficções de acordo com o uso e finalidades a elas destinadas.

Sempre que utilizadas para fins explicativos, as ficções funcionam como meio de integração de dados a serem apreendidos. Sempre que deliberadamente desnudam a sua ficcionalidade - apresentando-se desta forma como meras construções "como se" -, as ficcões atuam como meio de desestruturar e desorganizar os seus campos de referência extratextuais. As ficções explicativas são integradoras, já as literárias, dissipadoras precisamente por constituírem meios de exploração.

No entanto, o caráter integrador e dissipador de uma ficção dependerá de uma série de protocolos construídos e determinados historicamente que Iser sintetiza na noção de contrato de leitura:

É característico da literatura, em sentido lato, que se dá a conhecer como ficcional, a partir de um repertório de signos, assim assinalando que é literatura e algo diverso da realidade. [...] Deve-se, entretanto, ressaltar que este repertório de signos não se confunde com os sinais linguísticos do texto; razão porque fracassam todas as tentativas de mostrar o contrário Pois os sinais de ficção no texto assinalado são antes de tudo reconhecidos através de convenções determinadas e historicamente variadas, de que o autor e o público compartilham e que se manifestam nos sinais correspondentes. Assim, o sinal de ficção não designa nem mais a ficção, mas sim o "contrato" entre autor e leitor, cuja regulamentação o texto comprova não como discurso, mas como "discurso encenado". Deste modo, por exemplo, os gêneros literários se apresentam como regulamentações efetivas de largo prazo que permitem uma multiplicidade de variações históricas nas condições contratuais vigentes entre autor e público. Contudo, mesmo designações de curto prazo, específicas a certas situações, como a de "romance
7. ISER. O que é Antropologia literária?, p. 168. 
8. ISER. Atos de fingir ou o que é fictício no texto ficcional. p. 397.

9. HACKING. Historical ontology, p. 191. não-ficcional", funcionam do mesmo modo, porquanto a convenção é aí afirmada justamente por seu desmentido. ${ }^{8}$

Para Iser, a diferença entre ficção literária e ficção explicativa, ou aquilo que em alguns casos chamamos de não ficção, não pode ser aferida por qualquer dos repertórios de signos do texto, mas apenas pelas convenções estabelecidas a respeito do modo como os textos devem ser lidos ou usados. Nesse sentido, assim como é possível determinar um conjunto de convenções que indicam que o texto deve ser lido como uma ficção literária, seria possível também investigar os protocolos que indicam que um texto deve ser lido como um "candidato a verdade", segundo a expressão cunhada pelo filósofo Ian Hacking. ${ }^{9}$ Portanto, os conceitos de livro em Borges descrevem simultaneamente o artefato livro e o tipo de leitor que corresponde a esses livros. Os conceitos de livro-simulacro, livro sagrado e livro-nação, apesar de serem relacionados por Borges a certos momentos históricos, podem ser pensados como espécies de contratos de leitura que coexistem contemporaneamente. Essa relação recursiva entre o artefato livro e seu leitores é a síntese da hipótese antropológica do livro em Borges.

\section{O LIVRO-SIMULACRO}

O primeiro conceito de livro tratado por Borges é referido à antiguidade clássica e corresponde a algo que denominaremos livro-simulacro: "Los antíguos no professaban de nuestro culto del libro - cosa que me sorprende; veían en el libro un sucedáneo de la palabra oral". ${ }^{10}$ Quando Borges se refere aos "antigos", está esboçando uma caricatura do pensamento de Platão: "Tenemos el alto ejemplo de Platón, cuando dice que los libros son como efígies (puede haber estado pensando en esculturas o en cuadros), que uno cree que estan vivas, pero se preguntan algo no contestan”. ${ }^{11}$ Nesta citação, Borges está possivelmente se referindo à seguinte passagem do Fedro, na qual Sócrates argumenta que a escrita possui um inconveniente semelhante ao das pinturas:

- O uso da escrita, Fedro, tem um inconveniente que se assemelha à pintura. Também as figuras têm a atitude das pessoas vivas, mas se alguém as interrogar conservar-se-ão gravemente caladas. O mesmo sucede com os discursos. Falam das coisas como se as conhecessem, mas quando alguém quer informar-se sobre qualquer ponto do assunto exposto, eles se limitam a repetir sobre a mesma coisa. Uma vez escrito, um discurso sai a vagar por toda parte, não só entre os conhecedores mas também entre os que o não entendem, e nunca se pode dizer para quem serve e para quem não serve. Quando é desprezado ou injustamente censurado, necessita do auxílio do pai, pois não é capaz de defender-se nem de proteger-se por si. ${ }^{12}$
10. BORGES. Borges oral, p. 10

11. BORGES. Borges oral, p. 12

BELO HORIZONTE

v. 22

N. 3

SET.-DEZ. 2016

LEE. Uma hipótese sobre a dimensão antropológica [...]

P. $45-61$ 
Os problemas da escrita não concernem apenas ao grave silêncio que permanece quando interpelada, mas também a uma preocupação com um tipo de circulação indiscriminada do discurso escrito, um discurso incapaz de se defender e que não "sabe diante de quem convém falar e diante de quem é preferível ficar calado". ${ }^{13}$ A condenação da escrita nesse diálogo platônico está intimamente relacionada a uma preocupação com as condições de transmissão do saber. Transmissão da verdade ou da aparência de verdade?

Borges especula que a existência de grandes mestres orai na antiguidade clássica seria o principal sintoma dessa crença sobre o livro e a escrita, e cita como exemplo Pitágoras, que não escreveu deliberadamente por acreditar que assim suas ideias se manteriam vivas nas mentes de seus discípulos e passariam a ser propriedade destes. No entanto, a nossa crença contemporânea na suposta existência de mestres orais de um passado longínquo só se faz por nós conhecida através dos escritos e acaba por demonstrar o caráter ambíguo do conceito de livro-simulacro: se a escrita é uma cópia degradada, uma tentativa de capturar a sabedoria viva através de letras mortas, o outro lado dessa mesma moeda abre possibilidade ao contrato de leitura engendrado entre o livro sagrado e seu leitor. Pois o livro sagrado partirá do mesmo princípio de que a escrita é uma representação da fala, mas ao invés de ser uma cópia degradada, entra em cena a crença de que a escrita é uma espécie de documento, um vestígio material de uma voz de um grande mestre oral, cujo conteúdo é uma revelação de caráter suprassensível.

O tipo de contrato de leitura engendrado entre o livro-simulacro e seu leitor é uma atitude de suspeita permanente em relação a tudo que é escrito, pois a escrita seria o simulacro por excelência, o que permite justamente que Platão exemplifique a sua distinção entre aparência e verdade.

O mito egípcio da origem da escrita, narrado por Sócrates no texto de Platão, Fedro, sintetiza o jogo de valorações atribuídas à escrita que Borges faz equivaler ao conceito de livro-simulacro. O deus Thoth, que inventou os números, o cálculo, a astronomia e a geometria, o jogo de damas e os dados e também a escrita, certa vez foi ter com o deus Tamuz para mostrar-lhe as suas artes dizendo que elas deviam ser ensinadas aos egípcios. Quando chegaram à escrita, Thoth disse:

“- Esta arte, caro rei, tornará os egípcios mais sábios e lhes fortalecerá a memória, portanto com a escrita inventei um grande auxiliar para a memória e a sabedoria." Responde Tamuz: "- Grande artista Thoth! Não é a mesma coisa inventar uma arte e julgar da utilidade ou prejuízo que advirá aos que a exercerem. Tu, como pai da escrita esperas dela com o teu entusiasmo precisamente o contrário do que ela 
pode fazer. Tal coisa tornará os homens esquecidos, pois deixarão de cultivar a memória; confiando apenas nos livros escritos, só se lembrarão de um assunto exteriormente e por meio de sinais, e não em si mesmos. Logo, tu não inventaste um auxiliar para a memória, mas apenas para a recordação. Transmites aos teus alunos uma aparência de sabedoria, e não a verdade, pois eles recebem muitas informações sem instrução e se consideram homens de grande saber, embora sejam ignorantes na maior parte dos assuntos. Em consequência, serão desagradáveis companheiros, tornar-se-ão sábios imaginários ao invés de verdadeiros sábios”. ${ }^{14}$

Na fala do deus Tamuz o livro figura como algo que transmite uma aparência de memória ou sabedoria, mas nunca a verdade. $\mathrm{O}$ artefato livro está implicado sobretudo no problema da distinção entre verdade e aparência. $\mathrm{O}$ mito da origem da escrita desenha um sistema de valorações e oposições agonísticas, no qual a escrita tem um efeito atrofiante para memória, e o seu uso está associado aos "sábios imaginários" que devem ser discriminados dos "verdadeiros" sábios.

Em outras partes do diálogo repetem-se diversas alusões ao problema da distinção entre verdade e aparência, e ess polarização organiza os eixos a partir dos quais uma série de outras polarizações será implicada:
- Imagina que Lísias ou qualquer outro indivíduo tenha escrito ou escreva um dia a respeito de assuntos privados ou públicos; ou que venha escrever propostas legislativas, e que publique um livro político na convicção de possuir uma grande força lógica e convincente: isso mereceria censura. Porque ignorar, tanto no estado de vigília como em sonhos, o que é justo e o que não é, não saber distinguir o bom e o mau é coisa que não escapa à condenação, embora o povo inteiro louve semelhante homem. ${ }^{15}$

Neste breve trecho é possível assinalar algumas oposições: entre o bom e o mau, a verdadeira sabedoria e a opinião do povo, e entre o estado de vigília e o sonho. Em nota, o tradutor chama a atenção sobre as expressões gregas que significam "estar desperto" e "em sonho", e diz: "Trocadilho espirituoso e inimitável: as palavras gregas que indicam 'estar desperto' e 'em sonho' são muito semelhantes. O autor quer dizer que os escritores sem cultura filosófica são comparáveis a homens que estão sempre sonhando". ${ }^{16}$ A nota do tradutor demonstra mais uma derivação de sentido que associa a ausência da verdadeira sabedoria com o estado de sonho e as producõoes imaginárias. As inúmeras advertências de Sócrates com relação ao caráter nocivo do livro e da escrita estabelecem a imagem do livro como um artefato capaz de perturbar o julgamento da distinção entre verdade e aparência, entre memória e fantasia, que faz "ignorar, tanto no
15. PLATÃO Fedro, p. 123

16. PLATÃO. Fedro, p. 123 
17. PLATÃO. Fedro, p. 123

18. DALGALARRONDO. Psicopatologia e semiologia dos transtornos mentais, p. 148. estado de vigília quanto em sonho, o que é justo e o que não é, distinguir o que é bom e o que é mau”. Pois, ainda segundo uma fala subsequente de Sócrates, "um discurso escrito, não importa sobre qual assunto, possui forçosamente um grande número de fantasias". ${ }^{17}$

Tal perturbação resulta da ativação da imaginação e da fantasia que o discurso escrito ocasiona. E Borges parece, de algum modo, intuir a relação entre a fantasia, a imaginação e o discurso escrito ao descrever a função do livro a partir de uma relação indissociável entre memória e imaginação.

Que tal oposição entre memória e imaginação seja facilmente localizável por Borges na antiguidade clássica não significa que seus rastros não possam ser percebidos ainda hoje. Um exemplo de como essa oposição se encontra sutilmente disseminada pode ser encontrado nos manuais de Psicopatologia e Psiquiatria. Invariavelmente, nos capítulos sobre alteração da memória, dos manuais, consta o termo "fabulação", para descrever casos em que: "elementos da imaginação do doente ou mesmo lembranças isoladas completam artificialmente as lacunas de memória, produzidas, em geral, por déficit da memória de fixação”. ${ }^{18} \mathrm{O}$ fato de que uma disciplina contemporânea como a Psiquiatria necessite situar os limites entre o normal e o patológico entre a realidade e a fantasia, entre a lembrança legítima e a fabulação, na possibilidade de diferenciação entre os produtos da memória e da imaginação, revela a existência de uma extensa rede de crenças e valores que se organiza em torno da suposta incompatibilidade entre memória e imaginação. A nossa cultura certamente possui um olhar para o livro muito diferente daquele pelo qual o livro-simulacro era lido, mas de certa forma ainda permanecem resquícios pulverizados da crença que afirma a suposta incompatibilidade entre memória e imaginação, entre verdade e fantasia, e esta talvez seja a herança que faz do conceito de livro-simulacro um problema atual

\section{O LIVRO SAGRADO}

Se o contrato do livro-simulacro é baseado na suspeita permanente, o "livro sagrado" é a própria substância da verdade. Borges descreveu seu surgimento da seguinte maneira:

En la antigüedad hay algo que nos cuesta a entender, que no se parece a nuestro culto del libro. Se ve siempre en el libro a un sucedáneo de la palabra oral: pero luego llega del Oriente un concepto nuevo, del todo extraño a la antigüedad clásica: el del libro sagrado. Vamos a tomar ejemplos, empezando por el más tardío: los musulmanes. Éstos piensan que el Corán es anterior a la creación, anterior a la lengua árabe; es uno de los atributos de Dios, no una obra de Dios, es como su misericordia o su justicia. [...] Luego tenemos otros ejemplos más cercanos a nosotros: la Bíblia o, más concretamente, la Torá o 
19. BORGES. Borges oral, p. 14. el Pentateuco. Se considera que esos libros fueron dictados por el Espíritu Santo. Esto es un hecho curioso: la atribución de libros de diversos autores y edades a uno solo espíritu. ${ }^{19}$

O livro é considerado como um atributo de Deus, no caso do Corão; os Vedas expressam um caso curioso, no qual o livro é a própria origem do mundo. E Borges destaca também o caso do Pentateuco, que supõe a existência de uma divindade onisciente, uma inteligência infinita que dita diversas obras a diversos amanuenses. É importante assinalar o fato de que o livro sagrado, ao fornecer uma narrativa tanto da origem quanto da unidade do mundo - diferentemente do livro-simulacro, já que tal narrativa só seria crível no mundo antigo se a emissão de tal mensagem se desse pela oralidade -, transforma radicalmente as condições de estabelecimento dos contratos de leitura. Em primeiro lugar, a crença numa noção autoral supraindividual tornou coextensivos - ou, se quisermos explorar as analogias, religou - uma multiplicidade de textos dispersos no tempo e no espaço, engendrando a perspectiva da intertextualidade, de textos que tem relações intrínsecas com outros textos e que, portanto, devem ser lidos em conjunto, independentemente se escrito por amanuenses distintos

O livro sagrado é, segundo Oswald Spengler, aquilo que permite realizar a equação entre deus e a verdade:
As substance, truth is identical now with God, now with the Spirit of God, now with the Word. Only in the light of this can we comprehend sayings like "I am the truth and the life" and "My word is the truth," sayings to be understood, as they were meant, with reference to substance. Only so, too, can we realize with what eyes the religious man of this Culture looked upon his sacred book: in it the invisible truth has entered into a visible kind of existence, or, in the words of John i, 14: "The Word became flesh and dwelt among us." [...] A Magian revelation is a mystical process in which the eternal and unformed word of God or the Godhead as Word enters into a man in order to assume through him the manifest sensible form of sounds and especially of letters. ${ }^{20}$

O livro sagrado é o espaço no qual o processo místico pelo qual a substância, ilimitada, infinita e imponderável de Deus habita a realidade humana para, a partir disso, ganhar feições sensíveis e tornar-se manifesta, daí esse processo místico ser chamado de uma "revelação". Render feições sensíveis a uma realidade suprassensível equivale a fornecer uma forma narrativa a algo incognoscível. A narrativa contida nos livros sagrados permite ao homem integrar em uma unidade cósmica a eternidade e a infinita grandeza de Deus, algo que de outro modo não poderia ser experienciado por simples seres finitos.

Por tornar acessível o incognoscível, o livro sagrado demanda trabalho de decifração. O texto sagrado só pode
20. SPENGLER. The decline of the west, v. I, p. 244. 
21. BORGES. Borges oral, p. 16.

22. SCHLEIERMARCHER. Hermeneutics: the handwritten manuscripts, p. 110. tornar-se decifrável às custas da crença de que nele não existe contingência, tudo está absolutamente interligado, tudo é absolutamente determinado pela Inteligência infinita: "en ese libro nada es casual: ni el número de las letras ni la cantidad de sílabas de cada versículo, ni el hecho de que podamos hacer juegos de palabras com las letras, de que podamos tomar el valor numérico de las letras. Todo ha sido ya considerado", ${ }^{21}$ nos diz Borges.

Uma vez que se aceita o pressuposto de que no livro sagrado não há lugar para contingência, cria-se a necessidade de se assegurar a forma correta de interpretar o texto sagrado, tarefa que coube à hermenêutica. Friederich Schleiermacher diz que o limitado propósito de interpretar as escrituras sagradas deve se basear "on the assumption that misunderstanding occurs as a matter of course, and so understanding must be willed and sought at every point" ${ }^{22} \mathrm{~A}$ atitude de constante suspeita em relação ao livro-simulacro parece deslocar-se, no paradigma do livro sagrado, para as interpretações do leitor, pois seguir o pressuposto de Schleiermacher para a leitura de escrituras sagradas requer do leitor um intenso trabalho autorreflexivo e uma posição de permanente desconfiança das próprias interpretações que o leitor realiza.

A interpretação do livro sagrado desempenha funções fundamentais, pois combina aspectos textuais e rituais, liga as escrituras às significações existenciais, estabelece o sentido da
Lei como tradição escrita, traduz os desígnios divinos para a vida da comunidade e até estratifica essas comunidades pela autoridade e responsabilidade reservada aos intérpretes do livro sagrado.

O conceito de livro sagrado está intimamente relacionado com um uso específico da memória e da imaginação em favor da conservação das instituições, seja fornecendo origem e engendrando narrativas que tornem temporalidade algo discreto e pensável, seja pelo estabelecimento de relações de causa e efeito que resultam em um contexto moral absoluto e inegociável (os mandamentos, a lei do karma). É justamente na relação que certas narrativas estabelecem com os rituais e instituições que Frank Kermode procura traçar uma distinção entre o mito, narrativa própria do livro sagrado, e a ficção, característica do livro-nação:

We have to distinguish between myths and fictions. Fictions can degenerate into myths whenever they are not consciously held to be fictive. [...] Myth operates within the diagrams of ritual, which presupposes total and adequate explanations of things as they are and were; it is a sequence of radically unchangeable gestures. Fictions are for finding things out, and they change as the needs of sense-making change. Myths are the agents of stability, fictions the agents of change. Myths call for absolute, fictions for conditional assent. Myths make 
23. KERMODE. The sense of an ending, p. 39 .

24. BORGES. Borges oral, p. 17. sense in terms of a lost order of time, illud tempus as Eliade calls it; fictions, if successful, make sense of the here and now, hoc tempus. ${ }^{23}$

Enquanto o contrato de leitura da ficção pede um assentimento condicional, o mito pede o consentimento absoluto. Desse modo, a diferenciação entre mito e ficção proposta por Kermode sugere que possamos pensar o livro sagrado como uma metáfora para se compreender uma demanda específica da nossa civilização contemporânea para o artefato livro, qua seja, de atuar como agente de estabilização do sentido de realidade das instituições por se tratar de um modo socialmente sancionado de narrativa da origem.

\section{O LIVRO-NAÇÃO}

O terceiro conceito formulado por Borges é o "livro-nação", que é descrito a partir uma relação metonímica entre as individualidades do livro, do autor e da nação:

Luego decae la creencia en un libro sagrado y es remplazado por otras creencias. Por aquella, por ejemplo, de que cada país está representado por un libro. [...] Tenemos entonces un nuevo concepto, el que cada país tiene que ser representado por un libro; en todo caso, por un autor que puede serlo de muchos libros. $^{24}$
Através do conceito de livro-nação, Borges sugere uma relação de condicionamento mútuo entre a nação e o autor de ficções literárias. O livro-nação marca uma mudança de paradigma na qual a "revelação" da verdade "divina", de caráter universal, autoria de um único espírito que se manifesta em diversos indivíduos, é substituída pela ideia de uma verdade "estética", expressão do imaginário de um indivíduo, capaz de representar e sintetizar o espírito do povo e da nação. No entanto, o argumento de Borges procurará destacar que a relação da nação com o livro ou autor que a representa não é uma relação fundada exclusivamente na verossimilhança ou na homologia entre representante e representado. "Es curioso - no creo que esto haya sido observado hasta ahora - que los países hayan eligido indivíduos que no se parecen demasiado a ellos” ${ }^{25}$ São enumerados, então, no texto de Borges, alguns casos europeus que exemplificariam essa tese: a Inglaterra está representada por Shakespeare, mas se considerarmos que o típico do inglês é o understatement - ou seja, dizer um pouco menos das coisas -, as hipérboles e metáforas desse autor não causariam surpresas se ele fosse italiano ou judeu. No caso da Alemanha, "um país tão facilmente fanático", ${ }^{26}$ Goethe, um homem tolerante, a quem não importava tanto o conceito de nação. No caso da França, Borges confessa dificuldades em escolher um único autor, mas acaba por apontar uma tendência para Victor Hugo, que, a seu ver, é um estrangeiro na França, com suas grandes decorações e vastas metáforas. $\mathrm{Na}$
25. BORGES. Borges oral, p. 17

26. BORGES. Borges oral, p. 17 . 
27. BORGES. Borges oral, p. 17.

28. BRANDÃO. Grafias da identidade, p. 12

29. ANDERSON. Imagined communities, p. 4.

30. ANDERSON. Imagined communities, p. 6 .

Espanha, Cervantes, um homem tolerante, contemporâneo da Inquisição, não possui nem os vícios nem as virtudes espanholas. E Borges conclui: "Es como si cada país pensara que tiene que ser representado por alguien distinto, por alguien que puede ser, un poco, una suerte de remedio, una suerte de triaca, una suerte de contraveneno de sus defectos" ${ }^{27}$ Até que ponto os autores mencionados por Borges representam suas nações, ou até que ponto a escolha de tais autores é uma mera manifestação do gosto e do imaginário de Borges seria uma questão aberta a um debate interminável. Entretanto, o que desejaríamos reter do argumento de Borges é sua intuição a respeito das potencialidades da ficção literária, que "irrealiza a realidade nacional e simultaneamente realiza o imaginário nacional". ${ }^{28}$

O conceito de livro-nação, de Borges, aproxima-se das questões tratadas por Benedict Anderson em sua celebrada obra Imagined communities, publicada em 1983, posteriormente ao texto de Borges. Anderson procura demonstrar "dentro de um espírito antropológico, que a ideia de nação é um tipo particular de artefato". ${ }^{29}$ A nação é uma comunidade política imaginada, "it is imagined because even members of the smallest nation will never know most of their fellow members, meet them, or even heard of them, yet in the mind of each lives the image of their communion". ${ }^{30}$

E assim como Borges sugere que o "livro-nação" seja antecedido pelo "livro sagrado", Anderson, analogamente, aposta que a força da ideia de nação se deve, em larga medida, ao fato de que ela se configura como uma forma de resposta aos anseios de continuidade e sentido, deixados descobertos pela decadência das crenças religiosas e pela secularização racionalista:

The century of Enlightenment, the rationalist secularism, brought with it its own modern darkness. With the ebbing of religious belief, the suffering which belief in part composed did not disappear. Disintegration of paradise: nothing makes fatality more arbitrary. Absurdity of salvation: nothing makes another style of continuity more necessary. What then was required was a secular transformation of fatality into continuity, contingency into meaning. As we shall see few things were (are) better suited to this end than the idea of nation. ${ }^{31}$

Certamente, não se trata de um mero efeito de substituição do lugar da religião pela ideia de nação, embora seja interessante notar que ambos os artefatos, a nação e a religião, operam com significações que fornecem sentido a aspectos contingentes e uma noção de continuidade que transcende as vidas individuais, e que daí derivam certas consequências pragmáticas para a vida de uma determinada civilização. Para Anderson, as consequências pragmáticas são o
31. ANDERSON. Imagined communities, p. 11. 
32. ANDERSON. Imagined communities, p. 5.

33. ANDERSON. Imagined communities, p. 7. aspecto fundamental da comunidade imaginada. Não por acaso a nação seria forçosamente "imagined as both limited and sovereign", 32 a imaginação reifica a nação, confere a ela seus limites, sua unidade, e sua soberania, características que constituem as matrizes da identidade nacional, as bases para a identificação de um povo com a sua nação.

A consequência pragmática mais notável, engendrada por tal identificação, é que, apesar de toda exploração e desigualdade que pode estar, e está de fato, presente em uma nação, ela se constitui como um forte laço horizontal de fraternidade. "Ultimately, is fraternity what makes it possible, over the past two centuries so many millions of people, not so much to kill, as willingly to die for such a limited imaginings". ${ }^{33}$ Como essa significação imaginária é capaz de gerar sacrifícios tão colossais é para Anderson o problema central colocado pelo nacionalismo.

Se tanto o livro sagrado quanto o livro-nação narram origens e são capazes de inspirar nos humanos a imaginação de algo pelo qual valha a pena morrer, a principal diferença entre eles parece residir no fato de que, enquanto o livro sagrado afirma e confirma uma origem absoluta e a unidade do cosmos, o livro-nação não é capaz de afirmar uma origem absoluta, já que sua narrativa se liga a uma história secular. Por isso, qualquer origem que possa ser afirmada pelo livro-nação está exposta a um processo constante de subversão. Conceber a nação como objeto de uma verdade estética parece tornar visível não apenas a estrutura ficcional da ideia de nação, mas a sua demanda por um fluxo contínuo de narrativas, por um vir-a-ser que lance em direção ao futuro a promessa de uma comunidade.

O conceito de livro-nação revela a ambivalência da ficção: ao mesmo tempo que ela pode ser utilizada com a finalidade de conferir a unidade e a estabilidade à ideia de nação, reproduzindo pedagogicamente imagens que reafirmem tal estabilidade, ela também pode ser utilizada de modo a colocar em jogo a multiplicidade e as indeterminações da nação. $\mathrm{O}$ conceito de livro-nação, de Borges, sublinha uma das nuances do pensamento de Anderson e descortina as possibilidades específicas da ficção literária como algo capaz de intervir na soberania da nação, ao menos na soberania das produções de suas próprias imagens. Isso parece ser indicado pela ideia borgeana de que as ficções literárias são uma espécie de antídoto contra a estereotipia da nação. O texto literário comparece aí como um saber paradoxal, "que é tão mais vinculado à realidade quanto mais exercita sua autonomia em relação a ela”. ${ }^{34}$

\section{CONSIDERAÇÕES FINAIS}

Quando Borges expressou sua intenção de realizar uma "história do livro", em seguida comentou: "No me interesan
34. BRANDÃO Grafias da identidade, 
35. BORGES. Borges oral, p. 10.

36. BORGES. El libro de arena, p. 136 los libros fisicamente (sobretodo de los bibliofilos que suelen ser desmesurados), sino las diversas valoraciones que el libro ha recebido". ${ }^{35}$ A tentativa de nomear na ideia de "livro" algo que vai além do suporte físico, mas um espaço de interação entre o leitor e o texto, é uma tradução compatível da noção de artefato na Antropologia, que também procura descrever o espaço de uma relação recursiva entre o humano e seus artefatos.

O uso metafórico da ideia de um "espaço" que não se confunde com a dimensão física de um objeto pode parecer contraditória, mas podemos formular como parte de uma hipótese antropológica sobre livro na palestra de Borges sua função de instituir "endereços" dentro desse espaço virtual de interação entre livro e leitor. A contraprova dessa hipótese nos é dada pelo própria ficção de Borges em seu conto "El libro de arena”. Nesse conto, o livro de areia é considerado monstruoso porque tinha um número de páginas infinito, não tinha começo nem fim, e o seu leitor nunca conseguia encontrar uma página uma outra vez. A impossibilidade de assinalar endereços leva o narrador à constatação de que o livro de areia "era um objeto de pesadilla, una cosa obscena que infamaba e corrompía la realidad". ${ }^{36}$

De modo análogo, a suspeita dos antigos em relação aos livros tem a ver com o fato de que a escrita pretende-se uma cópia da voz, uma cópia cuja relação com seu original não pode ser assegurada. Para os antigos, o logos (discurso) está em estreita ligação com um corpo presente que é o seu endereço, a escrita é considerada um discurso órfão, pois não há quem venha a seu auxílio quando indagado, não consegue responder perguntas fornecendo explicações ou detalhes suplementares, apenas repetindo a si mesmo.

Quando Sócrates afirma, em Fedro, que todo discurso escrito possui necessariamente um grande número de fantasias, ele parece apontar para incapacidade que o próprio texto possui de preencher suas lacunas, forçando o leitor ao campo das fantasias. Esta descrição do texto escrito se aproxima da teoria da leitura de Iser, que compreende o texto literário como "segmentos determinados interligados por conexões indeterminadas". ${ }^{37} \mathrm{~A}$ indeterminação se apresenta ao leitor como lacunas que estimulam a imaginação do leitor no trabalho de fornecer determinação ao indeterminado. O paradigma do livro-simulacro engendra no contrato de leitura a suspeita do texto escrito justamente porque a escrita é a abertura para as contingências da comunicação que Platão gostaria de suprimir em sua supervalorização da voz. Daí que a escrita só pode ser uma aparência, um simulacro da voz, único veículo possível para a verdade.

Nesse sentido, o livro sagrado é uma concretização do desejo de Platão de suprimir as contingências, já que a crença subjacente no seu contrato de leitura é que ele é fruto de uma 
38. KERMODE. The sense of an ending, p. 4. inteligência infinita a quem não escapou um único detalhe. No entanto, se não há o que se suspeitar quanto à veracidade do livro, a contingência é deslocada para o leitor, o leitor deve suspeitar constantemente de sua capacidade de fazer sentido da verdade contida no livro sagrado. Com isso o livro sagrado acaba desempenhando a importante função de suprimir algumas lacunas que perturbam nossa capacidade de fazer sentido da vida. Segundo Frank Kermode, um dos modos de preencher tais lacunas "is to make objects in which everything is that exists in concord with everything else, and nothing else is - implying that this arrangement mirrors the disposition of a creator - actual or possible". ${ }^{8}$

O livro-nação estabelece uma quebra com o modelo unitário de verdade presente no paradigma de livro sagrado. Como já destacamos anteriormente, Borges enuncia como característica do livro-nação justamente a sua capacidade de ser uma espécie de antídoto para os estereótipos da nação. A noção de verdade deixa de estabelecer uma concordância total entre tudo que existe para poder dar lugar às fraturas da imagem da nação e às disputas internas quanto ao seu sentido. O livro-nação não é um único livro, mas aquilo que designa o espaço no qual se trava uma batalha entre diversos discursos que disputam a hegemonia do sentido da nação. Consoante com essa interpretação do livro-nação temos a afirmação de Edward Said:
O principal objeto de disputa no imperialismo é, evidentemente, a terra; mas quando se tratava de quem possuía a terra, quem tinha o direito de nela se estabelecer e trabalhar, quem a explorava, quem a reconquistou e quem agora planeja seu futuro - essas questões foram pensadas, discutidas e até, por um tempo, decididas na narrativa. Como sugeriu um crítico, as próprias nações são narrativas. O poder de narrar ou de impedir que se formem e surjam outras narrativas, é muito importante para a cultura e o imperialismo, e constitu uma das principais conexões entre ambos. Mais importante, as grandiosas narrativas de emancipação e esclarecimento mobilizaram povos do mundo colonial para que se erguessem e acabassem com a sujeição imperial; nesse processo, muitos europeus e americanos também foram instigados por essas histórias e seus respectivos protagonistas, e também eles lutaram por novas narrativas de igualdade e solidariedade humana. ${ }^{39}$

O conceito de livro-nação em Borges corresponde ao espaço para construção de narrativas que possam fornecer aos humanos não uma verdade absoluta tal como no livro sagrado, mas uma verdade estética, que pode servir de esteio para que a memória e a imaginação engendrem sonhos de emancipação e solidariedade entre certas comunidades humanas.
39. SAID. Cultura e imperialism, p. 8. 


\section{REFERÊNCIAS}

ANDERSON, Benedict. Imagined communities. New York London: Verso, 2006

BORGES, Jorge Luis. Borges oral. Madrid: Alianza Editorial, 1998

BORGES, Jorge Luis. El libro de arena. Madrid: Alianza Editorial 2003

BRANDÃO, Luis Alberto. Grafias da identidade: literatura contemporânea e imaginário nacional. Rio de Janeiro; Belo Horizonte: Lamparina; Fale (UFMG), 2005

KERMODE, Frank. The sense of an ending. New York: Oxford University Press, 2000.

ISER, Wolfgang. Atos de fingir ou o que é fictício no texto ficcional? In: LIMA, Luiz Costa. Teoria da literatura em suas fontes. Rio de Janeiro: F. Alves, 1983. p. 383-458.

ISER, Wolfgang. O que é antropologia literária? In: ROCHA, João Cezar de Castro (Org.). Teoria da ficção: indagações à obra de Wolfgang Iser. Trad. Bluma Waddington Vilar, João Cezar de Castro Rocha. Rio de Janeiro: Eduerj, 1999. p. 150-182.

ISER, Wolfgang. Teoria da recepção. In: ROCHA, João Cezar de Castro (org.). Teoria da fiç̧ão: indagações à obra de Wolfgang Iser. Trad. Bluma Waddington Vilar, João Cezar de Castro Rocha. Rio de Janeiro: Eduerj, 1999. p. 22-46.

LEROI-GOURHAN, André. Gesture and speech. Transl. Anna Bostock Berger. Cambridge, Massachusetts: MIT Press, 1993.
PLATÃO. Fedro. Trad. Alex Marins. São Paulo: Martin Claret, 2004

SAID, Edward. Cultura e imperialismo. Trad. Denise Bottmann. São Paulo: Companhia de Bolso, 2011.

SCHLEIERMARCHER, Friedrich Daniel. Hermeneutics: The Handwritten Manuscripts. Transl. James Duke and Jack Forstman. Missoula: Heinz Kimmerle, 1977.

SPENGLER, Oswald. The decline of the west. Transl. Charles Francis Atkinsons. New York: Oxford University Press, 1995. 